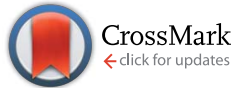

Cite this: RSC Adv., 2015, 5, 69184

\title{
Gold-dotted hydroxyapatite nanoparticles as multifunctional platforms for medical applications
}

\author{
Catarina Ferreira dos Santos, ${ }^{\text {ab }}$ Pedro Sousa Gomes, ${ }^{\text {cd }}$ Maria Margarida Almeida, \\ Marc-Georg Willinger, ${ }^{f}$ Ralf-Peter Franke, ${ }^{g}$ Maria Helena Fernandes ${ }^{c d}$ \\ and Maria Elisabete Costa*e
}

A novel synthetic approach for coupling metallic gold nanoparticles (AuNPs) to the facets of hydroxyapatite crystalline nanoparticles (HapNPs) without an additional reducing agent was developed. Hexagonal prism-shaped hydroxyapatite nanoparticles (HapNPs) were first precipitated by a hydrothermal route assisted by citric acid, which left behind carboxylate species adsorbed on the HapNP facets. HapNP were then used as templates for gold precipitation. Upon exposure to gold ions, the carboxylate species on the HapNP prismatic facets were able to trigger the nucleation of metallic gold by reducing the gold ions in situ. The used conditions did not allow for the extensive growth of gold nuclei and hence gold dots with diameters not larger than $2.5 \mathrm{~nm}$ were formed on the HapNP facets. The obtained (Hap-AuNP) heteronanostructures combine Hap nanoprisms, a highly biocompatible material easily recognised by the human body, with metallic nanosized gold that imparts a plasmon resonance (SPR) effect to the synthesized nanostructures, which is of great potential for further exploration within the contexts of thermotherapy and imaging strategies. Human mesenchymal stem cells were exposed to a range of Hap-AuNP concentrations, but no cytotoxic effects from the heteronanostructures were observed. Furthermore, Hap-AuNP greatly enhanced Runx2 and ALP expressions. In addition, these results predict that the synthesized Hap-AuNP particles could hold potential interest for medical applications requiring nontoxic materials capable of bonedefect repair and furthermore exhibiting SPR properties, which can be potentially advantageous for therapeutic and diagnostic purposes.

Received 22nd June 2015 Accepted 23rd July 2015

DOI: $10.1039 / c 5 r a 11978 b$

www.rsc.org/advances

\section{Introduction}

The unprecedented developments in materials synthesis and characterization techniques at the nanoscale level are encouraging audacious approaches in matter manipulation and assembly, which are being exploited for designing nanostructures with improved or new properties and functionalities compared with their bulk counterparts. Nanomedicine is one of the numerous fields wherein such cutting-edge nanotech

${ }^{a}$ Department of Mechanical Engineering, Escola Superior de Tecnologia de Setúbal, Instituto Politécnico de Setúbal, Setúbal, Portugal

${ }^{b} I C E M S$, Instituto Superior Técnico, Technical University of Lisbon, Av. Rovisco Pais, Lisboa 1049 001, Portugal

${ }^{c}$ Laboratory for Bone Metabolism and Regeneration, Faculdade de Medicina Dentária, Universidade do Porto, Portugal

${ }^{d}$ MedInUP - Center for Drug Discovery and Innovative Medicines, University of Porto, Porto, Portugal

${ }^{e}$ Department of Materials and Ceramics Engineering, CICECO, Aveiro Institute of Materials, University of Aveiro, 3810-193 Aveiro, Portugal. E-mail: elisabete.costa@ ua.pt

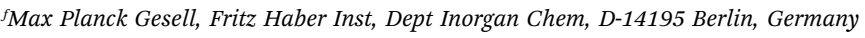
${ }^{g}$ Central Institute for Biomedical Technology, Biomaterials Division, University of Ulm, Ulm, Germany advancements are fostering innovative strategies similar to that of cancer theranostics. ${ }^{1}$

Gold nanoparticles (AuNP) are an emblematic example of biomedical nanostructures with a well-known surface plasmon resonance effect (SPR), the frequency of which is affected by nanoparticle (NP) size, shape, inter-distance and refractive index of surrounding NP media. This effect has been largely exploited for labeling and probing a wide variety of biomolecules that interfere with AuNP dispersed states and with the refractive index of the NP environment due to adsorption. ${ }^{2}$ Such applications demand a close control of AuNP morphological attributes (size and shape) and in particular, of AuNP dispersed conditions. These prerequisites have been covered by a large number of publications and hence various proposals for AuNP production, including synthetic methods, reagents, solvents, and stabilizers, are found in recent literature. Currently, AuNPs are also being explored as photothermal contrast agents for cancer imaging and therapy., ${ }^{3,4}$ Plasmonic AuNP strategically located in tumors are used to enhance near-infrared laser absorption and heat dissipation and thus produce a local temperature increase that disturbs cellular functions, resulting in cell death. In addition, the X-ray absorbing properties of 
AuNPs can be also used for biodistribution data acquisition enabling non-invasive tumor imaging and 3D reconstruction., Other treatment methods exploit spherical AuNP as sensitizing agents in radio frequency ablation and X-ray radiation cancer therapies. $^{3,6-8}$

Hydroxyapatite (Hap) is an appealing inorganic biomaterial. Its chemical composition, crystalline structure and particle morphology if appropriately engineered can replicate the chemical and physical attributes of the inorganic components of human bone and teeth ${ }^{9,10}$ while offering enhanced adsorptive ability towards a considerable number of biomolecules and drugs. ${ }^{11,12}$ Addressing the combination of the exceptional properties of AuNPs and Hap and benefiting from the easy functionalization of AuNPs for specific protein binding, hybrid hydroxyapatite gold nanoparticles (Hap-AuNPs) structures with a portfolio of interesting properties for various bioapplications, such as immunosensing, ${ }^{13}$ bone-tissue regeneration ${ }^{12,14,15}$ and improvement of hemocompatibility, ${ }^{15,16}$ have been frequently reported. The methods found for the production and/or assembly of Hap-AuNPs structures are quite diverse. ${ }^{\mathbf{1 3 - 1 6}}$ However, gold and Hap particles are often precipitated separately and then assembled to form the composite material. ${ }^{12,13,16,17}$ The Turkevich method ${ }^{18}$ or a variant of it is still seen as the method of choice for AuNP synthesis, whereas no preferred method could be identified for Hap synthesis because of the successful implementation of multiple techniques. ${ }^{19}$ Frequently, polymers (e.g. collagen and chitosan) are required as linkers or agents for the coupling of gold and Hap. ${ }^{14,15,17}$ One simple method for producing uniform Hap nanoparticles (HapNPs) is hydrothermal synthesis in the presence of an organic chelating ion or molecule ${ }^{\mathbf{2 0 - 2 3}}$ used as a shape tailoring agent that allows the control of particle size and shape. ${ }^{24,25}$ According to recent reports, citrate ions could modulate prismatic HapNPs under specific hydrothermal synthetic conditions. $^{23}$

The present study addresses AuNP nucleation and growth onto the surface of HapNPs for producing organized composite nanostructures. The ability of citric ions to play a dual role, i.e. as a HapNP tailoring agent and as an in situ reducing reagent of $\mathrm{Au}^{3+}$ leading to local $\mathrm{Au}^{0}$ nucleation and growth on HapNP facets is the engineering tool exploited herein. From an application perspective, widespread potential is anticipated, considering the benefits of obtaining accurate control over the size, shape and surface chemistry of AuNPs with the high biocompatibility of HapNP. Due to bone affinity, biomimetic features and osteointegrity, HapNP is particularly suited for bone-related applications. ${ }^{26,27}$ Thus, in addition to the interest in AuNP usage as an excellent contrast element ${ }^{28,29}$ depending on its size, the SPR tunability is envisaged with great usefulness for imparting simultaneous imaging and therapeutic abilities to Hap-AuNPs nanostructures, which makes them powerful tools for differentiated bone applications. Therefore, another point of interest is the discussion of the potential effects of HapNP assembled with AuNPs on the proliferation and differentiation of human mesenchymal stem cells due to their role in bone metabolism and regeneration, an issue that has not been covered so far.

\section{Materials and methods}

\subsection{Hydroxyapatite synthesis}

A previously reported hydrothermal precipitation method ${ }^{30}$ was followed for HapNP synthesis. The starting precursor solution was prepared in the following manner: a $0.6 \mathrm{M}$ citric acid monohydrate $\left(\mathrm{C}_{6} \mathrm{H}_{8} \mathrm{O}_{7} \cdot \mathrm{H}_{2} \mathrm{O}\right)$ (Riedel-deHaën, 99.5\%) solution was mixed with a $0.2 \mathrm{M}$ calcium nitrate $\mathrm{Ca}\left(\mathrm{NO}_{3}\right)_{2} 4 \mathrm{H}_{2} \mathrm{O}$ (RiedeldeHaën, 99\%) solution and a $0.2 \mathrm{M}$ ammonium hydrogen phosphate $\left(\mathrm{NH}_{4}\right)_{2} \mathrm{HPO}_{4}$ (Merck, 99\%) solution was then added. The $\mathrm{pH}$ of the solution was adjusted to 8.1 with small additions of a $25 \%$ ammonia solution (Riedel-deHaën). The final solution was poured into a $100 \mathrm{ml}$ Teflon vessel, filling up $50 \%$ of the total vessel volume. The Teflon vessel was then sealed in a stained-steel autoclave and subsequently transferred into an oven at $180{ }^{\circ} \mathrm{C}$ wherein it was held under autogenous pressure for 24 hours. The autoclave was then quenched in water at room temperature. Finally, the precipitated particles were collected and filtered using a glass Millipore filter vessel and then dried in a desiccator.

\subsection{Gold precipitation}

For the precipitation of gold, $86.5 \mu \mathrm{l}$ of a hydrogen tetrachloroaurate $\left(\mathrm{HAuCl}_{4}\right)$ solution was added to $500 \mathrm{ml}$ of deionized water in order to obtain a $0.25 \times 10^{-3} \mathrm{M}$ gold solution with $\mathrm{pH}$ of $\sim 3.25 \mathrm{ml}$ of the gold solution was then heated at $\sim 100{ }^{\circ} \mathrm{C}$ for $3 \mathrm{~min}$ and $50 \mathrm{mg}$ of HapNP was subsequently added, which was synthesized as described in Section 2.1. The resulting suspension was maintained under boiling conditions for a period of $5 \mathrm{~min}$. The overall procedure was repeated for covering various reaction times, i.e. boiling times of $10 \mathrm{~min}$ and $20 \mathrm{~min}$. The particles (Hap-AuNP) were then repeatedly washed with deionized water during filtration with a glass Millipore filter vessel and then dried in a desiccator.

\subsection{Particle characterization}

The morphology of all particles obtained by precipitation was evaluated through electron transmission microscopy (TEM) using a Hitachi H-9000-NA microscope operated at $200 \mathrm{kV}$ and high-resolution electron transmission microscopy (HRTEM) images were obtained on a JEOL 2200 FS microscope operating at $200 \mathrm{kV}$. For TEM analysis, the particles were dispersed with 2-propanol and scattered over copper grids coated with a formvar film, and TEM images were used to determine AuNP sizes. More than 100 particles were randomly counted to determine the particle size distribution using Image-J software. Particle crystalline phases were identified by powder X-ray diffraction (XRD) analysis (Rigaku PMG-VH with $\mathrm{CuK} \alpha$ radiation = $1.5405 \AA$ A). Fourier transform infrared spectroscopy (FTIR) was performed to identify the functional groups using a Mattson Galaxy 3020 spectrophotometer. The test samples were prepared by mixing $\sim 2 \mathrm{mg}$ of the precipitated particles with $\sim 300 \mathrm{mg}$ of spectroscopic-grade $\mathrm{KBr}$ (Merck), followed by shaping the mixture into a disk. The infrared spectra were acquired in transmittance mode in the region of $4000-400 \mathrm{~cm}^{-1}$ with a resolution of $4 \mathrm{~cm}^{-1}$. The UV-vis absorption data were collected on a Shimadzu MPC-3100 PC series spectrophotometer 
using an auto scan between 200 and $700 \mathrm{~nm}$. The specific surface area (SSA) of the obtained particles was determined through $\mathrm{N}_{2}$ adsorption using a Micromeritics Gemini 2370 V5 Series. The samples were thoroughly degassed for $24 \mathrm{~h}$ at $120{ }^{\circ} \mathrm{C}$ before nitrogen adsorption. The SSA was determined based on the multipoint Brunauer-Emmett-Teller isotherm (BET). ${ }^{20}$

\subsection{Interaction of Hap-AuNPs with human mesenchymal stem cells}

Human mesenchymal stem cells-bone marrow-derived (HMSC$\mathrm{bm}$, Innoprot), according to the supplier, were found to stain positive for CD44 and CD90, which are characteristic markers of the population phenotype. Third subculture cells were used to evaluate the cell response to the nanoparticles.

HMSC, $10^{4}$ cells per $\mathrm{cm}^{2}$, was cultured in Minimum Essential Medium Eagle, alpha modification ( $\alpha$-MEM, Sigma-Aldrich) containing $10 \%$ fetal bovine serum (FBS, Sigma-Aldrich), $50 \mu \mathrm{g} \mathrm{ml} \mathrm{ml}^{-1}$ ascorbic acid, penicillin (10 units per $\mathrm{ml}$ )/ streptomycin $\left(2.5 \mu \mathrm{g} \mathrm{ml}^{-1} ; \mathrm{P} / \mathrm{S}\right.$ solution, Sciencell $)$ and $2.5 \mu \mathrm{g}$ $\mathrm{ml}^{-1}$ of Fungizone. After $24 \mathrm{~h}$, the medium was removed and a completely fresh culture medium containing sterilized HapNP or Hap-AuNPs-1, 10, 100 and $500 \mu \mathrm{g} \mathrm{ml} \mathrm{m}^{-1}$ - was added to the adherent cells. Cultures were further incubated for 1, 3 and 7 days without any medium change. Cultures without nanoparticles were used as controls. Incubation was carried out under a humidified atmosphere of $95 \%$ air and $5 \% \mathrm{CO}_{2}$ at $37{ }^{\circ} \mathrm{C}$. Cultures were characterized in the following manner at days 1, 3 and 7.

DNA content. DNA content was analyzed by the PicoGreen DNA quantification assay (Quant-iT ${ }^{\mathrm{TM}}$ PicoGreen ${ }^{\circledR}$ dsDNA Assay Kit, Molecular Probes Inc., Eugene), according to the manufacturer's instructions. Cultures were treated with Triton X-100 (0.1\%; Sigma-Aldrich), and fluorescence was measured on an Elisa reader (Synergy HT, Biotek) at wavelengths of 480 and $520 \mathrm{~nm}$ for excitation and emission, respectively, and corrected for reagent blank fluorescence. The amount of DNA was calculated by extrapolating a standard curve obtained by running the assay with the given DNA standard.

Cellular viability. $\mathrm{MTS}^{31}$ and $\mathrm{LDH}^{32}$ assays were used to estimate cell viability. The MTS assay is based on the reduction of an MTS tetrazolium compound [3-(4,5-dimethylthiazol-2-yl)5-(3-carboxymethoxyphenyl)-2-(4-sulfophenyl)-2H-tetrazolium] to a purple formazan product by a mitochondrial reductase enzymes system on viable cells. An MTS solution (Cell Titer 96®) Aqueous One Solution Cell Proliferation Assay, Promega), $20 \mu \mathrm{l}$, was added to the culture medium (100 $\mu \mathrm{l}$, 96-well plates), and cultures were incubated for $4 \mathrm{~h}$ (in a humidified atmosphere of
$95 \%$ air and $5 \% \mathrm{CO}_{2}$ at $37{ }^{\circ} \mathrm{C}$ ). The absorbance was measured at $492 \mathrm{~nm}$ on an ELISA reader (Synergy HT, Biotek). The lactate dehydrogenase ( $\mathrm{LDH}$ ) assay is based on the reduction of NAD by the action of $\mathrm{LDH}$ released to the medium due to cell damage (plasma membrane integrity) or lysis. The resultant reduced $\mathrm{NAD}(\mathrm{NADH})$ is used in the stoichiometric conversion of a tetrazolium dye. Total LDH determination was performed using the lactate dehydrogenase-based in vitro toxicology assay kit (Sigma-Aldrich; St. Louis, Mo.), according to the manufacturer's instructions. The amount of $\mathrm{LDH}$ leakage to the medium was normalized to total LDH. Results are expressed in the percentage of cell viability compared with the control.

CLSM observation. Cultures were fixed (3.7\% methanol-free formaldehyde, $15 \mathrm{~min}$ ), permeabilized with $0.1 \%$ Triton and incubated with bovine serum albumin (Sigma-Aldrich) and $10 \mathrm{mg} \mathrm{ml} \mathrm{m}^{-1}$ in PBS $(1 \mathrm{~h})$ to block non-specific interactions. Cytoskeleton filamentous actin (F-actin) was visualized by treating permeabilized cells with Alexa Fluor ${ }^{\circledR}$ 488-conjugated phalloidin (Invitrogen), 1:100 in PBS (20 min). Cells were counterstained with propidium iodide (Sigma Aldrich), 10 $\mathrm{mg} \mathrm{ml} \mathrm{m}^{-1}$ in PBS (5 min). Stained samples were mounted in Vectashield ${ }^{\circledR}$ (Vector laboratories) and examined in a Leica SP5 AOBS (Leica Microsystems®) microscope.

Gene expression by RT-PCR. Adherent $24 \mathrm{~h}$ HMSC were exposed to $100 \mu \mathrm{g} \mathrm{ml}{ }^{-1}$ HapNP or Hap-AuNPs for three days and were evaluated for the expression of the housekeeping gene GAPDH (glyceraldehydes-3-phosphate dehydrogenase) and the osteoblastic genes Runt-related transcription factor 2 (RUNX-2), alkaline phosphatase (ALP), osteocalcin (OC) and osteoprotegerin (OPG). RNA was extracted using an RNeasy® Mini Kit (QIAGEN), according to manufacturer's instructions. RNA was quantified by measuring the absorbance of the samples at $260 \mathrm{~nm}$. RNA, $0.5 \mu \mathrm{g}$, was reverse transcribed and amplified (25 cycles) with the Titan One Tube RT-PCR System (Roche) at an annealing temperature of $55{ }^{\circ} \mathrm{C}$. Table 1 shows the primers used in the RT-PCR analysis. After electrophoresis on $1 \%(\mathrm{w} / \mathrm{v})$ agarose gel, the bands were analysed through densitometry with the ImageJ 1.41 software. Values were normalized to the corresponding GAPDH value of each experimental condition.

ALP activity. ALP activity was evaluated in cell lysates $(0.1 \%$ Triton $\mathrm{X}-100,5 \mathrm{~min}$ ) by the hydrolysis of $p$-nitrophenyl phosphate in an alkaline buffer solution ( $\mathrm{pH}$ of $\sim 10.3 ; 30 \mathrm{~min}, 37^{\circ} \mathrm{C}$ ) and colorimetric determination of the product ( $p$-nitrophenol) at $400 \mathrm{~nm}$ in an ELISA plate reader (Synergy HT, Biotek). ALP activity was normalized to total protein content (quantified by Bradford's method) and expressed as nmol $\mathrm{min}^{-1} \mathrm{mg}_{\text {protein }}{ }^{-1}$.

Table 1 Primers used on RT-PCR analysis

\begin{tabular}{lll}
\hline Gene & Forward primer & Reverse primer \\
\hline GAPDH & CAGGACCAGGTTCACCAACAAGT & GTGGCAGTGATGGCATGGACTGT \\
Runx2 & CAGTTCCCAAGCATTTCATCC & TCAATATGGTCGCCAAACAG \\
COL1 & TCCGGCTCCTGCTCCTCTTA & ACCAGCAGGACCAGCATCTC \\
ALP & ACGTGGCTAAGAATGTCATC & CTGGTAGGCGATGTCCTTA \\
OC & CACTCCTCGCCCTATTG & CCCACAGATTCCTCTTCT \\
OPG & AAGGAGCTGCAGTAGGTCAA & CTGCTCGAAGGTGAGGTTAG
\end{tabular}


Statistical analysis. Three independent experiments were performed; in each experiment, six replicas were set up for the biochemical assays and two replicas for the qualitative assays. The results are presented as mean \pm standard deviation (SD). Data groups were evaluated using a two-way analysis of variance (ANOVA), and no significant differences in the pattern of the cell behavior were found. Statistical differences between the experimental groups were assessed by Bonferroni's method. Values of $p \leq 0.05$ were considered statistically significant.

\section{Results and discussion}

\subsection{Synthesis of functionalized hydroxyapatite nanosized particles (HapNP)}

Literature reports on hydroxyapatite synthetic methods are plentiful. The choice of a particular synthetic methodology is normally dictated by the particle morphology and/or crystallinity criteria. In the present case, a previously reported hydrothermal precipitation method ${ }^{23}$ was selected to obtain crystalline HapNP with nanometric dimensions and welldefined facets easily imaged using electron microscopy. In addition, other issues, including the surface chemistry of the precipitated particles, were taken into account.

Fig. 1(a) shows an image of HapNP as synthesized by the hydrothermal procedure. As observed, the particles display a light-yellowish colour. The crystalline phase composition of these particles is revealed by the XRD pattern presented in Fig. 2 (curve (a)), the diffraction peaks of which can be assigned to hydroxyapatite (Hap), according to the JCPDS no. 09-0432. Fig. 3(a) shows the FT-IR spectrum of the precipitated HapNP in which the characteristic peaks of hydroxyapatite are detected. ${ }^{33-35}$ Furthermore, several features attributed to the organic groups are also identified in a range from $1680 \mathrm{~cm}^{-1}$ to $1350 \mathrm{~cm}^{-1}$ (Fig. 3(b)). The band at $1384 \mathrm{~cm}^{-1}$ may be ascribed to $\mathrm{CH}_{2}$ scissoring, and carboxylate groups differently coordinated to the Hap surface under monodentate or bidentate configurations ${ }^{6,30}$ may account for the bands at 1402, 1458, 1577 and $1669 \mathrm{~cm}^{-1}$. Such adsorbed carboxylate species $\left[\mathrm{R}\left(\mathrm{COO}^{-}\right)_{x}\right]_{\mathrm{ads}}$ can be interpreted as the original citrate ion fingerprints that might have decomposed under the temperature and pressure regime used for Hap synthesis, in line with the reports on citric acid thermal degradation. ${ }^{36-39}$
The particle morphology assessed by TEM and shown in Fig. 4(a) and (b) can be well described by a hexagonal prismatic shape with a width $(w)$ of between 20 and $30 \mathrm{~nm}$ and a length $(l)$ ranging from $50 \mathrm{~nm}$ to $100 \mathrm{~nm}$. These nanoscale dimensions of the prismatic hydroxyapatite nanoparticles (HapNP) account for a large specific surface area of $55 \mathrm{~m}^{2} \mathrm{~g}^{-1}$ and an aspect ratio $(l / w)$ larger than 1.7. Fig. 4(b) shows the HRTEM image of a HapNPs wherein well-defined lattice fringe patterns are observed. The distance between adjacent lattice fringes corresponds to an interplanar distance of $0.65 \mathrm{~nm}$ that can be indexed to the $d$-spacing values of the hydroxyapatite crystal (010) planes, which are parallel to the $c$ axis. The applied citratemediated hydrothermal synthesis thus favored preferential HapNP growth along the $c$-axis, which resulted in elongated particle morphology.

The interaction of citric acid with the HapNP surface and its effects on HapNP growth have been frequently addressed, from both experimental and theoretical perspectives. Calcium phosphate precursor solutions containing citric acid have been reported to favor the precipitation of HapNP with elongated shapes under varied conditions of temperature and pressure. ${ }^{23}$ According to computer simulation studies, ${ }^{33,40}$ a strong binding of citric acid or of citrate ion to Hap lateral prismatic facets may slow their growth rates and as a result, enable their dominant expressions on the final particle morphology. Such theoretical predictions might explain the current results assuming that citrate ions at an early stage of the hydrothermal processing and citrate-derived moieties at a later stage of the precipitation perform as lateral growth inhibitors, hence contributing to particle shapes. An accurate illustration of citrate's role under the temperature and pressure regime of this study requires a complete follow-up of the interplay among Hap nucleation, growth and citrate degradation progress, which is now an ongoing study.

\subsection{Templating gold precipitation with HapNP}

HapNP synthesized by a hydrothermal technique were used as substrates for AuNP growth. The effects of gold precipitation time were examined to assess its impact on the gold particle size and size distribution.

Gold particle crystal structure, morphology and SPR. Fig. 1(b)-(d) allows one to follow the colour evolution of the

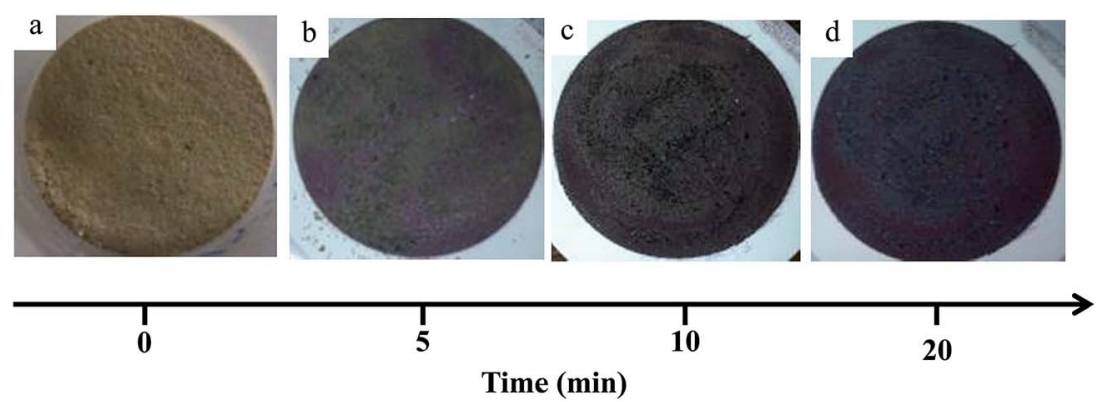

Fig. 1 Optical images of hydroxyapatite nanoparticles: (a) as synthesized at $180^{\circ} \mathrm{C}$ (HapNPs) and after submission to gold precipitation (HapAuNPs) during (b) $5 \mathrm{~min}$, (c) $10 \mathrm{~min}$ and (d) $20 \mathrm{~min}$. The particle colour evolution denotes the presence of metallic gold. 


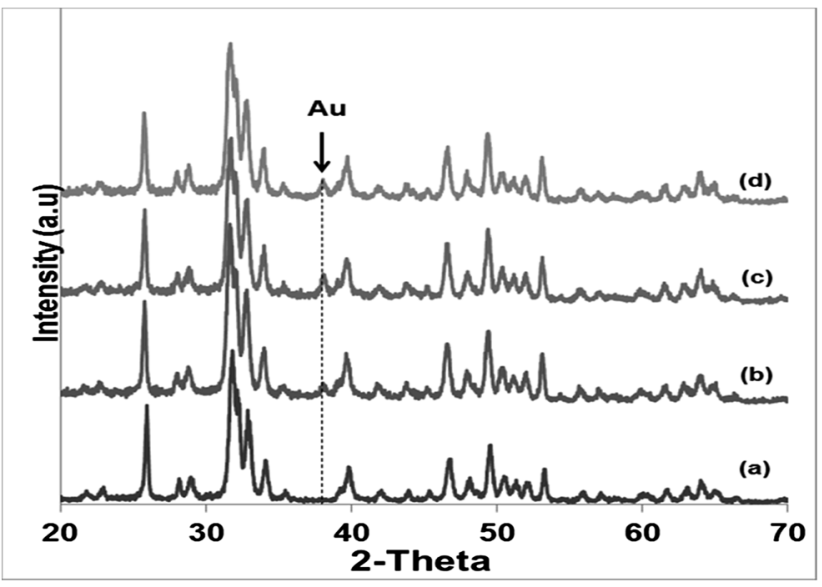

Fig. 2 X-ray diffraction patterns of hydroxyapatite nanoparticles: (a) as produced at $180{ }^{\circ} \mathrm{C}$ (HapNPs) and after submission to gold precipitation (Hap-AuNPs) during (b) $5 \mathrm{~min}$, (c) $10 \mathrm{~min}$ and (d) $20 \mathrm{~min}$. The peak detected at $2 \theta \sim 38^{\circ}$ is assigned to metallic gold.

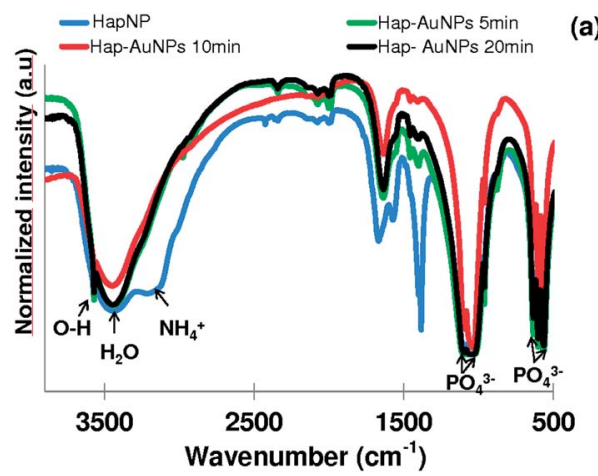

(b)

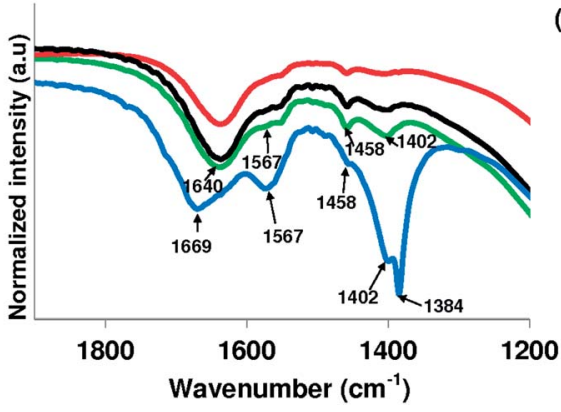

Fig. 3 FTIR spectra of (a) HapNPs synthesized at $\left.180^{\circ} \mathrm{C} \mathrm{(}\right)$ and its evolution with metallic gold precipitation after $5 \mathrm{~min}(\square), 10 \mathrm{~min}$ $(\square)$ and $20 \mathrm{~min}\left({ }^{\prime}\right) ;\left(\right.$ b) the $1200-1900 \mathrm{~cm}^{-1}$ spectral region is amplified.

HapNP after submitting to the gold precipitation experimentation during various reaction times. The original yellowish colour of HapNP gives way to a purple colour as precipitation occurs, hence anticipating the presence of nanometric-sized gold particles in the Hap-AuNPs powders. ${ }^{19}$ Further evidence of gold precipitation is provided by the XRD patterns shown in Fig. 2(b)-(d), wherein the peak detected at $2 \theta \sim 38^{\circ}$ was identified as the more intense metallic gold peak, ${ }^{41}$ according to the JCPDS no. 071-4614.
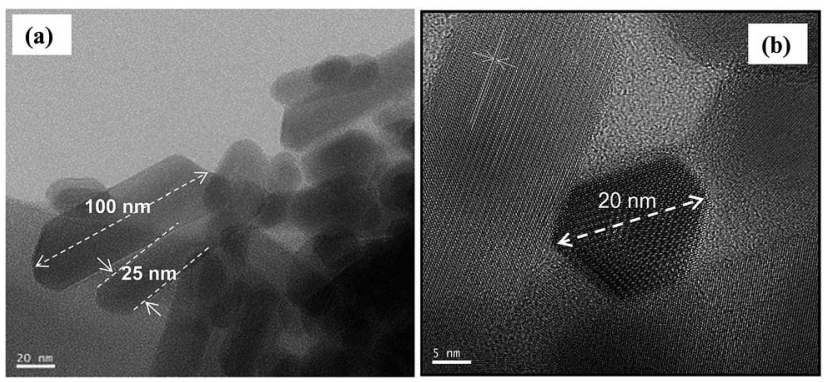

Fig. 4 (a) TEM images showing the elongated prismatic shape of HapNPs. (b) The hexagonal base of prismatic particles is confirmed on a particle top view.

Fig. 5(a) and (b) shows the HRTEM images of the Hap-AuNPs particles collected after various precipitation times. It is clearly observed that the prismatic HapNP previously imaged in Fig. 4(a) are now uniformly spotted with nanosized dark dots, the dimensions of which vary approximately from 1.5 to $2.5 \mathrm{~nm}$ as the synthesis time increases from 5 min (Fig. 5(a)) to $20 \mathrm{~min}$ (Fig. 5(b)). These are nanosized dots of metallic gold that were precipitated on HapNP facets, accounting for the HapNP colour variation previously described. It was also found that HapAuNPs after 20 min of reaction time apparently have a lower density of larger AuNPs dots on their surfaces as documented by the particle-size distribution curves (Fig. 5(c)). This may be explained by an Ostwald ripening mechanism favouring the growth of larger AuNPs at the expense of the smaller. ${ }^{19}$ Although the dots become larger, they apparently preserve the spherical shape, which is known to be the lowest-energy shape, often observed among metal nanoparticles obtained from the reaction of metal salts with reducing agents. ${ }^{42}$ The present strategy proved to be highly reproducible, consistently coupling uniform spherical AuNPs to HapNPs.

Fig. 6 shows the UV-vis spectra of as-prepared HapNP (a) and of Hap-AuNPs after $5 \mathrm{~min}$ (b) and $20 \mathrm{~min}$ (c) of synthesis. No UV-vis band is detected in the range of $300-800 \mathrm{~nm}$ for asprepared HapNP, which confirms previous reports. ${ }^{41}$ In contrast, a characteristic SPR band of AuNPs is clearly observed around $550 \mathrm{~nm}$ in the Hap-AuNPs spectra. The observed SPR accounts for the strong colour changes observed on the parti$\operatorname{cles}^{29}$ and confirms the formation of spherical AuNP by this synthetic method, which is in good agreement with the TEM results. Moreover, it was observed that the SPR band is similar for the two selected precipitation times, which may be related to the small variation in particle size, which is insignificant for detection by using UV-vis in powders. The SPR band shift from the well-known value of $520 \mathrm{~nm}$ reported for isotropic spherical gold particles $(<20 \mathrm{~nm})$ dispersed in water ${ }^{43,44}$ to the observed value herein of $\sim 550 \mathrm{~nm}$ may reflect the influence of the substrate (Hap) refractive index (1.64), which is larger than that of water (1.33), to which the surrounding medium is generally referred. ${ }^{45} \mathrm{~A}$ similar shifting effect was also reported for gold nanoparticles of $\sim 5.5 \mathrm{~nm}$ deposited over $\mathrm{SiO}_{2} / \mathrm{Si}$ substrates. ${ }^{46}$

Mechanism of gold precipitation. The process of AuNPs growth on the HapNP surface was also followed by FTIR spectral analysis for the purpose of assessing the modifications on 

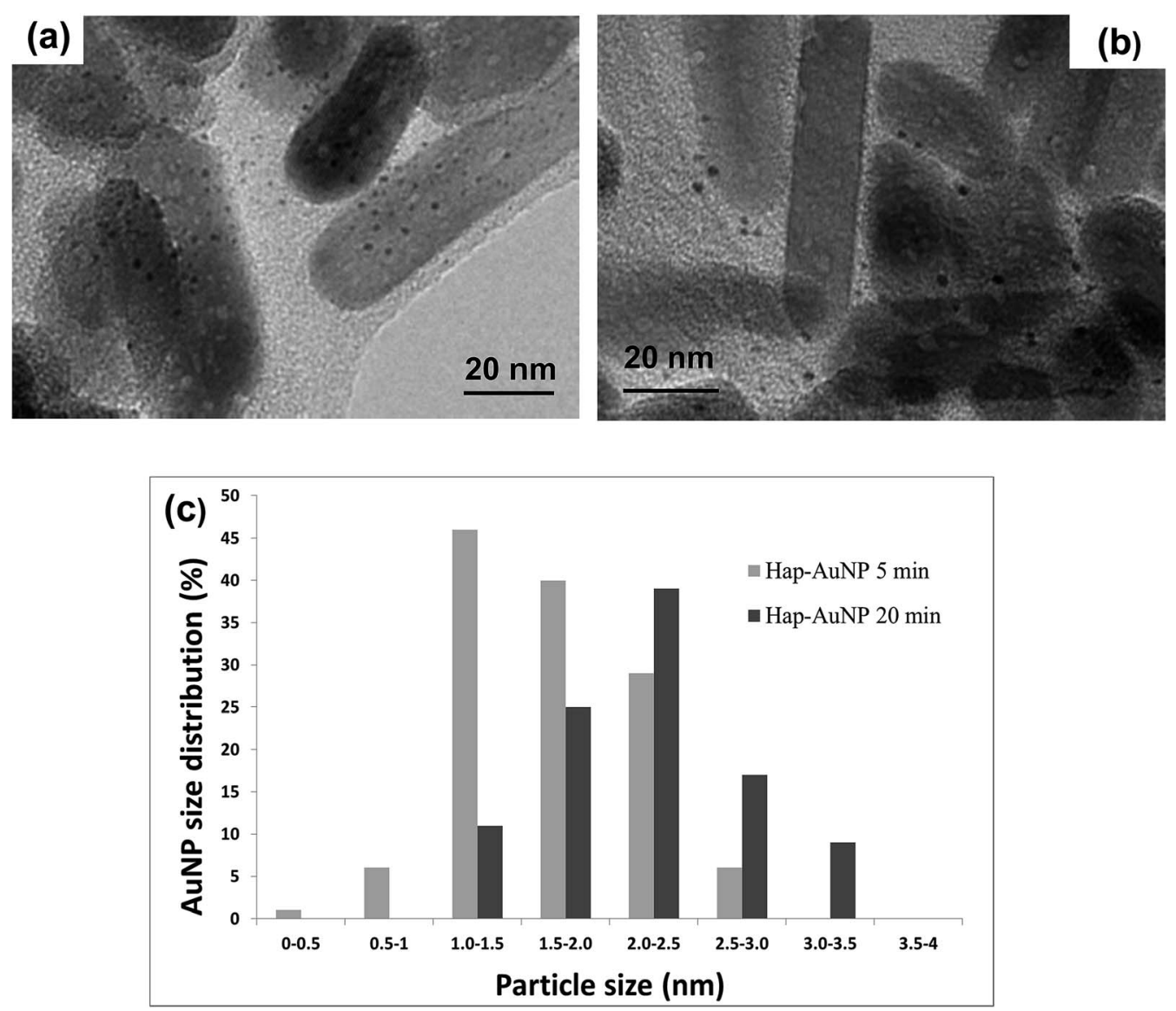

Fig. 5 HRTEM images of Hap-AuNPs collected after two different precipitation times: (a) 5 min and (b) 20 min. The particles are spotted with nanosized dark dots of metallic gold (AuNP), which were precipitated on HapNP facets. (c) AuNP size distribution precipitated after 5 min and $20 \mathrm{~min}$.

adsorbed species. Fig. 3(a) compares the full spectrum of HapNP as prepared with those of Hap-AuNPs collected after 5, 10 and $20 \mathrm{~min}$, with the details of the carbonate region
(1350-1680 $\mathrm{cm}^{-1}$ ) magnified in Fig. 3(b). Although characteristic Hap features are observed in all the spectra, several differences are observed in the $1350-1700 \mathrm{~cm}^{-1}$ region as gold

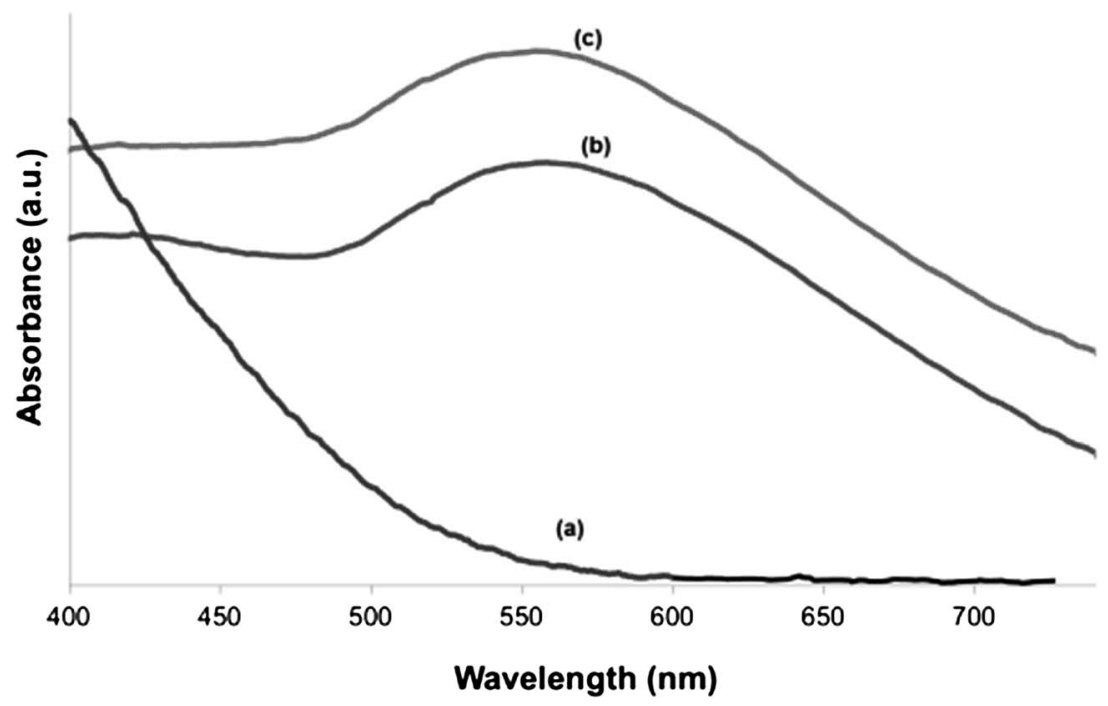

Fig. 6 UV-vis spectra of (a) HapNPs synthesized at $180^{\circ} \mathrm{C}$ and after reacting with the gold solution (Hap-AuNPs) during (b) 5 min and (c) 20 min. The characteristic surface plasmon resonance band of gold nanoparticles is clearly observed at $\sim 552 \mathrm{~nm}$ for the Hap-AuNPs. 
precipitation proceeds (Fig. 3(b)). In this spectral slot wherein citrate-derived species containing carboxylate groups coordinated differently to HapNP surfaces are expected to be detected, ${ }^{47}$ several features are observed to have disappeared or undergone a strong intensity decrease as observed for the bands at 1384,1567 and $1670 \mathrm{~cm}^{-1}$, although the bands at $1402 \mathrm{~cm}^{-1}$ and $1458 \mathrm{~cm}^{-1}$ remain unaffected by the Au synthetic process. These results indicate that some adsorbed species containing $\mathrm{COO}^{-}$groups may be appropriately configured to participate in Au nucleation, ${ }^{\mathbf{4}}$ whereas other groups appear to be less strategic in the metallic precipitation.

As referred by Kumar et al., ${ }^{48}$ gold precipitation in a bulk solution by the Turkevich method can be systematized according to the following steps. An initial step comprises the oxidation of citrate $\left(\mathrm{CH}_{2} \mathrm{COO}^{-}\right)_{2} \mathrm{C}(\mathrm{OH}) \mathrm{COO}^{-}$to an acetone dicarboxylic acid $\left(\mathrm{CH}_{2} \mathrm{COO}^{-}\right)_{2} \mathrm{CO}$ accompanied by the reduction of auric salt $\left(\mathrm{AuCl}_{3}\right)$ to aurous salt $(\mathrm{AuCl})$. The subsequent step requires the disproportionation of $\mathrm{AuCl}$ into gold atoms $\left(\mathrm{Au}^{0}\right)$ and $\mathrm{AuCl}_{3}$, as schematized by the equation $3 \mathrm{AuCl} \rightarrow 2 \mathrm{Au}^{0}+$ $\mathrm{AuCl}_{3}$. This last step requires various aurous chloride molecules to be in a nearby condition, which is facilitated by an acetone dicarboxylic species that tethers molecular aurous chloride.

In this study, gold precipitation took place on the HapNP surface, most likely on the lateral prismatic faces as confirmed by TEM images. When HapNPs are added to the reagent $\mathrm{HAuCl}_{4}$ aqueous solution ( $\mathrm{pH}$ of $\sim 3$ ), HapNPs acquire a neutral or weakly positive zeta potential ${ }^{23}$ that favours electrostatic attachment of negatively charged auric complexes, i.e. $\left[\mathrm{AuCl}_{3}\right.$ $\mathrm{OH}]^{-}$and/or $\left[\mathrm{AuCl}_{2} \mathrm{OH}_{2}\right]^{-}$, which are abundant species in an $\mathrm{HAuCl}_{4}$ solution at $\mathrm{pH} 3-4 .^{\mathbf{4 9 , 5 0}}$ It is herein proposed that $\left[\mathrm{R}\left(\mathrm{COO}^{-}\right)_{x}\right]_{\text {ads }}$ groups undergo oxidation under the thermal conditions of the precipitation process $\left(T=100{ }^{\circ} \mathrm{C}\right)$, thus enabling the reduction of the auric complexes on the HapNP surface to aurous species and mimicking the role of acetone dicarboxylic acid reported by Kumar et al. ${ }^{48}$ Furthermore, the vicinity of the resulting aurous species will present an advantageous condition for the disproportionation reaction to proceed towards $\mathrm{Au}^{0}$ nucleation.

Although previous reports have shown that gold precipitation may take place on pristine oxide surfaces wherein $\mathrm{O}^{-}$or $\mathrm{OH}^{-}$are the protagonist surface species interacting with solution gold complexes, ${ }^{49-51}$ long precipitation times are thus required ( $\geq 1 \mathrm{~h}$ ) compared with the few minutes reported in this study. The applied HapNPs thus behaved as a substrate that prompted the heterogeneous nucleation of AuNPs without the addition of any reducing agent such as $\mathrm{NaBH}_{4}$, one of the most commonly used reagents for gold ion reduction. ${ }^{44}$ Another method for the deposition of gold on the surface of Hap nanoparticles was reported by J.-D. Wang et al. ${ }^{52}$ By using urea as a precipitating agent, a gold precursor $\left(\mathrm{Au}(\mathrm{OH})_{3}\right)$ was precipitated, which was later converted to metallic gold upon heat treatment at $350{ }^{\circ} \mathrm{C}$. Therefore, compared with that synthesis route, the present method offers a straightforward way to produce metallic gold, exempting any precipitating agent or intermediate calcination step. The carboxylic species attached to the HapNP surface are thus a strategic tool for in situ gold reduction and nucleation hence leading to AuNPs uniformly distributed on HapNP facets, without the need of any additional surfactant for stabilization. ${ }^{19}$ Being attached to HapNP surfaces, AuNPs are not prone to aggregation, thereby eliminating potential drawbacks associated with aggregates.

Recent reports examined the multiple functionalities attributed to AuNP, several of which in a concerted manner may convey performance synergy in the field of therapeutics. ${ }^{53,54}$ In the present case, the coupling of AuNPs to HapNPs imparts an SPR effect to the resulting composite nanostructure, which could be further exploited for thermotherapy: AuNPs are envisaged to empower HapNPs with hyperthermic capability for treating near-surface tumours or skin-type cancers wherein laser requirements are less strict as compared to tumours located deep within bodily tissue for which a laser light in the near-infrared (NIR) region of the biological water window $(650-900 \mathrm{~nm})$ would be recommended. ${ }^{29}$ Moreover, HapNPs can also behave as drug delivery systems (DDS) ${ }^{55}$ due to their ability in the adsorption and release of therapeutic drugs. ${ }^{55}$ The endowment of a thermal response afforded by AuNPs to such DDS could open the possibility of customizing a HapNP-based DDS to a target of interest. It was reported that the addition of a thermo-responsive coating to a DDS would allow for the use of induced thermal stimulus to trigger drug delivery only at the local area of interest, ${ }^{56}$ thus confining the drug effects to the unhealthy tissue while minimizing drug losses before the diseased cells are reached. In addition to thermotherapeutic benefits, AuNPs may also provide imaging capabilities as demonstrated in a recent study wherein the ability of gold nanoparticles to perform as a CT imaging contrast agent for tumour imaging was reported. ${ }^{54}$ Therefore, the hydroxyapatite-based nanostructures (Hap-AuNPs) engineered in the present study offer promising characteristics for thermotherapeutic and imaging functionalities. The exploration of such attributes will warrant significant interest because it may lead to the expansion of hydroxyapatite applications beyond its wellknown medical use in hard-tissue regeneration.

\subsection{Interaction of Hap-AuNPs with human mesenchymal stem cells}

As previously mentioned, because of the similarity of Hap to the mineral phase of bone tissue and thus its natural bone affinity and biocompatibility, a range of bone-tissue-related applications are envisaged for HapNPs. ${ }^{26,27}$ In a previous study, HapNPs similar to those reported herein proved to be non-toxic to MG63 osteoblastic cells in terms of cell viability/proliferation, F-actin cytoskeleton organization and apoptosis rate. In addition, they increased the expression of ALP and BMP- $2 .{ }^{23}$ In order to assess the potential of the synthesized Hap-AuNPs for bone-related applications, the particles obtained after $5 \mathrm{~min}$ of reaction time were selected to be cultured with human bone marrow - derived mesenchymal stem cells - due to their potential in bone regenerative approaches. HMSC were cultured under standard culture conditions, with the medium supplemented by ascorbic acid, because of its role in the synthesis of the bone collagenous extracellular matrix ${ }^{57}$ but in the absence of any osteogenic inducer. HMSC cell response to the NPs was assessed for cell viability/proliferation and osteoblastic-related markers. 
(a)

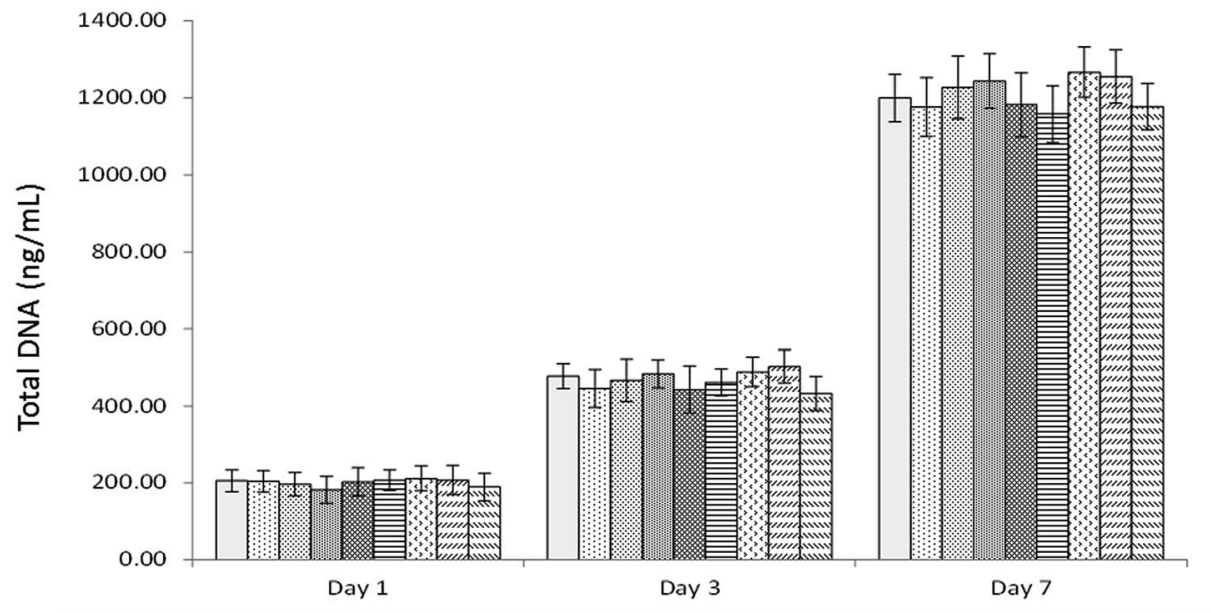

(b)

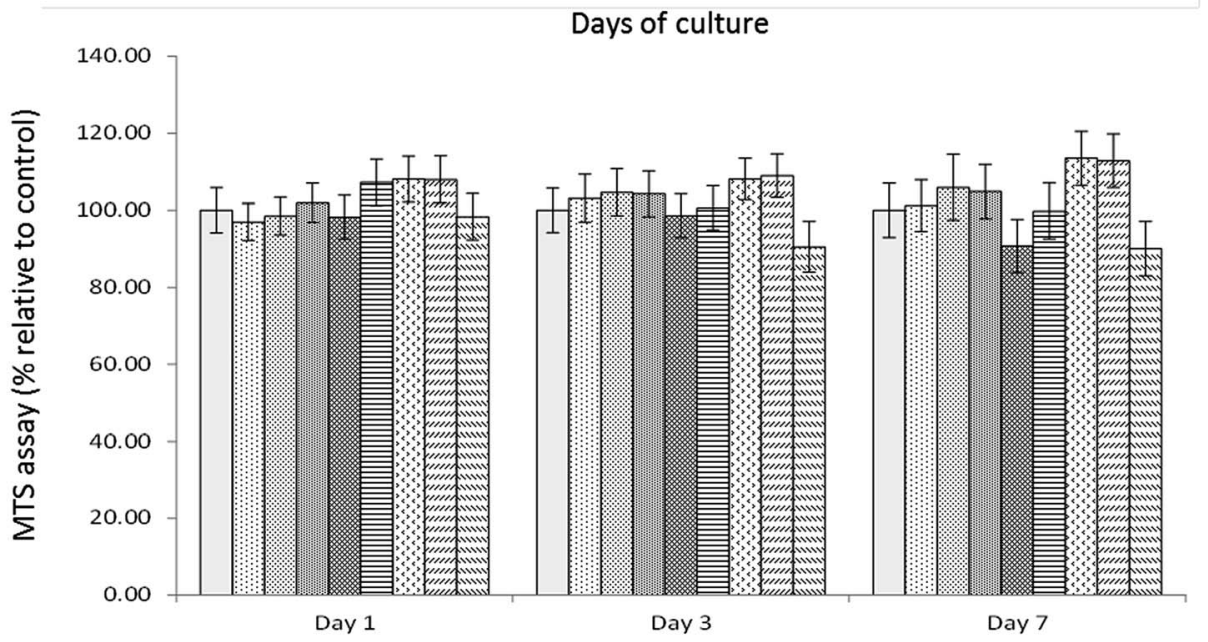

(c)

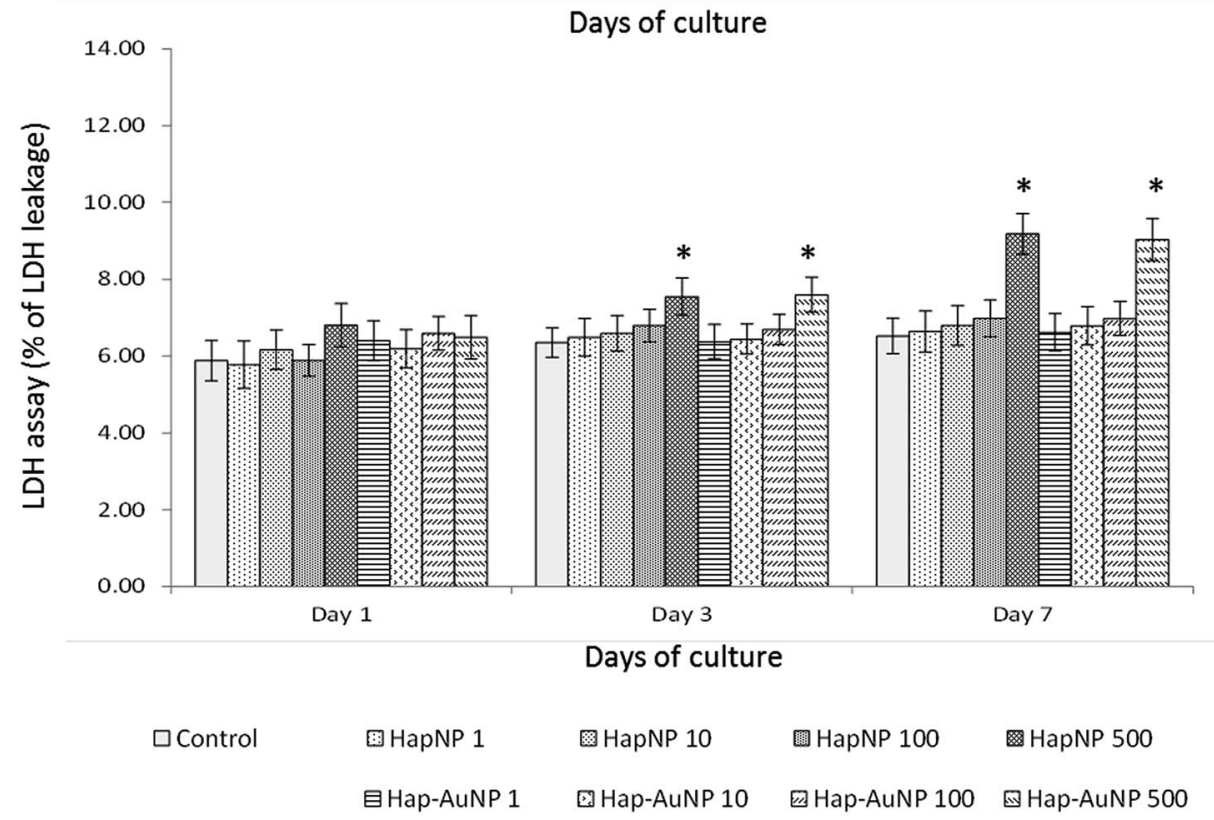

Fig. 7 (a) DNA content, (b) MTS reduction and (c) LDH leakage of HMSC cultured for 1, 3 and 7 days in the presence of HapNPs and Hap-AuNPs,

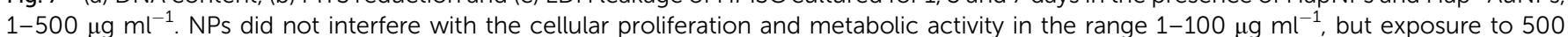
$\mu \mathrm{g} \mathrm{ml}^{-1}$ caused a slight decrease in cellular viability. *Significantly different from control (absence of NPs). 
DNA content. The DNA content of control cultures (in the absence of NPs) increased throughout the culture time. Comparatively, exposure to HapNP or Hap-AuNPs (1-500 $\left.\mu \mathrm{g} \mathrm{ml}^{-1}\right)$ did not result in any obvious effects. As the DNA content reflects the number of cells present in the cultures, this observation suggests that the two nanoparticles did not interfere in HMSC proliferation. Results are shown in Fig. 7(a).

Cellular viability. The viability of HMSC grown with the NPS was assessed by MTS reduction and LDH release assays. Results for the MTS assay, mostly based on the reduction ability of cell mitochondrial dehydrogenases by viable cells, showed similar values for the control and NPs-exposed cultures, as shown in Fig. 7(b). However, cultures exposed to 10 and $100 \mu \mathrm{m} \mathrm{ml}^{-1} \mathrm{NPs}$ for 7 days displayed a slight increase in metabolic activity, which attained statistical significance for Hap-AuNPs nanoparticles. On the other hand, cultures treated with $500 \mu \mathrm{g} \mathrm{ml}$ HapNP or Hap-AuNPs, for a period of seven days, displayed a slight decrease, suggesting lower reduction ability. On the LDH assay shown in Fig. 7(c), the LDH released in the medium throughout the culture time revealed low values on the control cultures and those exposed to 1-100 $\mu \mathrm{g} \mathrm{ml}^{-1}$ NPs, suggesting minimal deleterious effects on cell membrane integrity; however, an increase was observed in the presence of the higher nanoparticle levels $\left(500 \mu \mathrm{g} \mathrm{ml}^{-1}\right)$, following three and seven days of exposure, suggesting a somewhat compromised cell viability. Nevertheless, the increase on the percentage of $\mathrm{LDH}$ leakage was only around 9\% after seven days of exposure, compared with $\sim 6.5 \%$ in the control cultures. These observations are in line with that observed in the MTS assay.

F-actin cytoskeleton. The observation of cultures under CLSM, following staining for F-actin cytoskeleton and nucleus counterstaining, corroborated the low toxicity profile of HapNP and Hap-AuNP particles. The cell adhesion to the culture substrate and the subsequent cytoplasmic expansion were similar in both the absence and presence of the nanoparticles. On day 1 , cells displayed an elongated morphology, establishing elementary cell-to-cell contacts. A high cell growth rate was then noticed. On day 3 , areas of high cell density were already visualized and on day 7, cultures showed confluent zones with continuous cellular multilayers. Cells exhibited a well-organized F-actin cytoskeleton with intense staining at the cell boundaries, prominent nucleus and ongoing cell division, which are signs of mechanical integrity and a healthy behaviour. Representative images are shown in Fig. 8 for the cultures exposed to $100 \mu \mathrm{g} \mathrm{ml}{ }^{-1}$ NPs. The F-actin cytoskeleton, which is highly concentrated just beneath the plasma membrane, provides structural stability and elasticity to the cell undergoing substrate adaptation, but it is also a key player in the cellular mechano-transduction mechanisms modulating complex signalling pathways, such as Rho family GTPases, which affects overall cellular behaviour. ${ }^{58}$ Thus, these results further support the cytocompatibility of HapNP and Hap-AuNPs towards mesenchymal stem cells.

Osteoblastic gene expression. In addition, gene expression by a reverse-transcription polymerase chain reaction (RT-PCR) was performed to investigate osteogenic signal expression in the presence of HapNP and Hap-AuNPs $\left(100 \mu \mathrm{g} \mathrm{ml}^{-1}\right)$, shown in Fig. 9(a). Hap-AuNPs greatly induced the expression of Runx2 ( $\sim 100 \%$ ) compared with the slight increase observed in HapNPs. This is an interesting finding, as Runx2 is the earliest transcription factor for the osteogenic differentiation pathway, and in addition, it is a master regulator for the expression of multiple late-stage genes as a determinant for osteoblastic differentiation

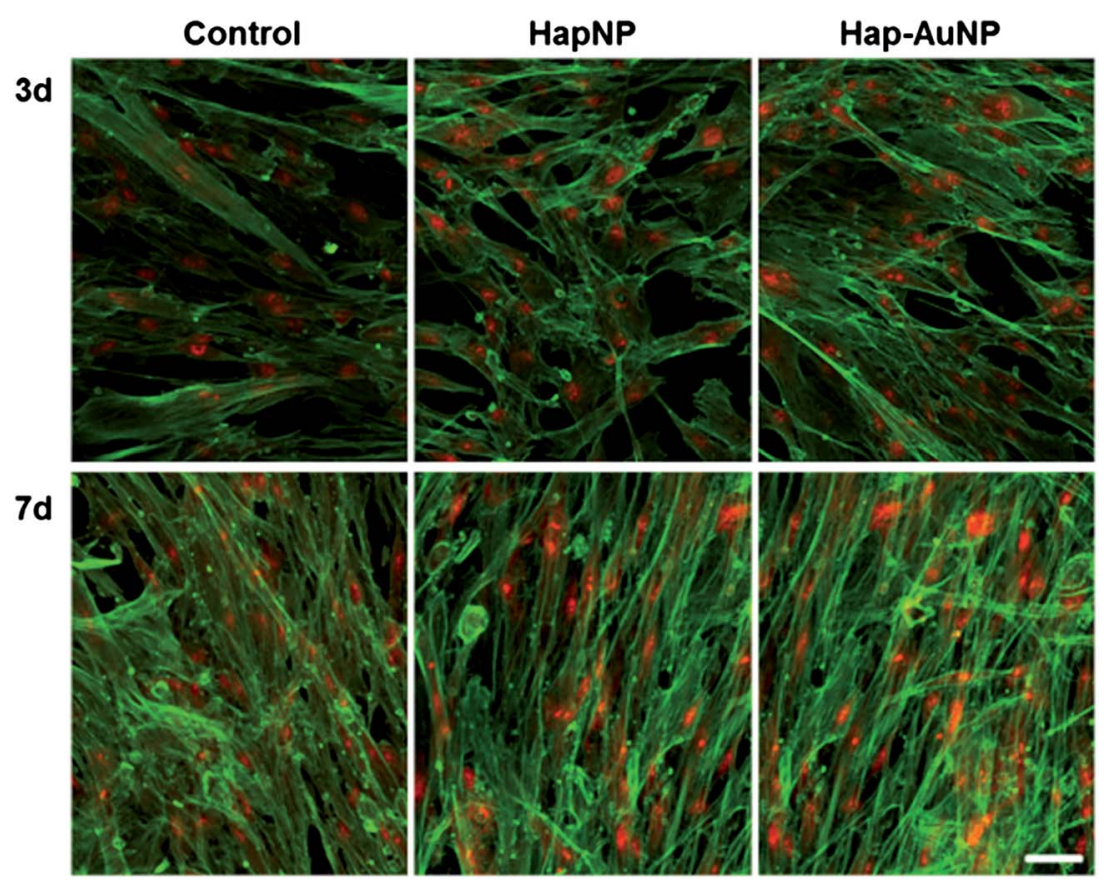

Fig. 8 Representative confocal laser scanning microscopy images of HMSC cultured for 3 and 7 days in the presence of HapNPs and HapAuNPs, $100 \mu \mathrm{g} \mathrm{ml}^{-1}$. Cultures were stained for the cytoskeleton (green) and nucleus (red). Cellular morphology and organization of the cell layer were similar in control and NP-exposed cultures. Bar: $50 \mu \mathrm{m}$. 
and bone formation. ${ }^{57}$ Both the particles showed a trend for an increase in the expression of $\mathrm{Col} 1$, the main component of the bone extracellular matrix, synthesized during the proliferative stage of the osteoblastic differentiation pathway. ${ }^{57}$ It can be noted that Hap and Hap-AuNPs had a significant impact in ALP expression with more than a fourfold increase in the expression level of this early osteoblastic differentiation marker. Osteocalcin expression, a late osteoblastic differentiation marker, with a role in the regulation of crystal growth, ${ }^{57}$ was not particularly affected by HapNP or Hap-AuNPs. This suggests that these particles appear to not interfere in the regulatory mechanisms of the matrix mineralization. The expression of OPG, a key molecule in the interplay between osteoblasts and osteoclasts during bone remodelling, was not affected by Hap but was slightly reduced in the presence of Hap-AuNPs.

ALP activity. Cultures exposed to HapNP and Hap-AuNPs $\left(100 \mu \mathrm{g} \mathrm{ml}^{-1}\right)$ were also assessed for ALP activity. In line with the increased gene expression for this enzyme, ALP activity was greatly induced by the two nanoparticles. The inductive effect was observed already after one day of exposure but greatly increased at day 3 and $7(\sim 150 \%$ and $\sim 80 \%$, respectively; Fig. 9(b)). ALP, a hallmark of osteoblastic differentiation, is synthesized during the early matrix formation and maturation periods. This enzyme has an essential role in the onset of matrix mineralization, by providing phosphate ions which, together with calcium ions, ensure the chemical conditions for the osteoblastic-mediated mineral deposition. ${ }^{57}$

Literature reports on the interaction of osteoblastic lineage cells with Hap nanoparticles show a great variability of results, which is expected considering the wide-ranging versatility and diversity of the physicochemical properties of the tested particles, cell system and experimental protocols..$^{23,59-63}$ However, regarding the present HapNP, the observed cell response is in line with previous reports showing low cytotoxicity of Hap nanoparticles towards osteoblastic cells, in addition to their ability to modulate cell proliferation and differentiation events. Upon exposure to
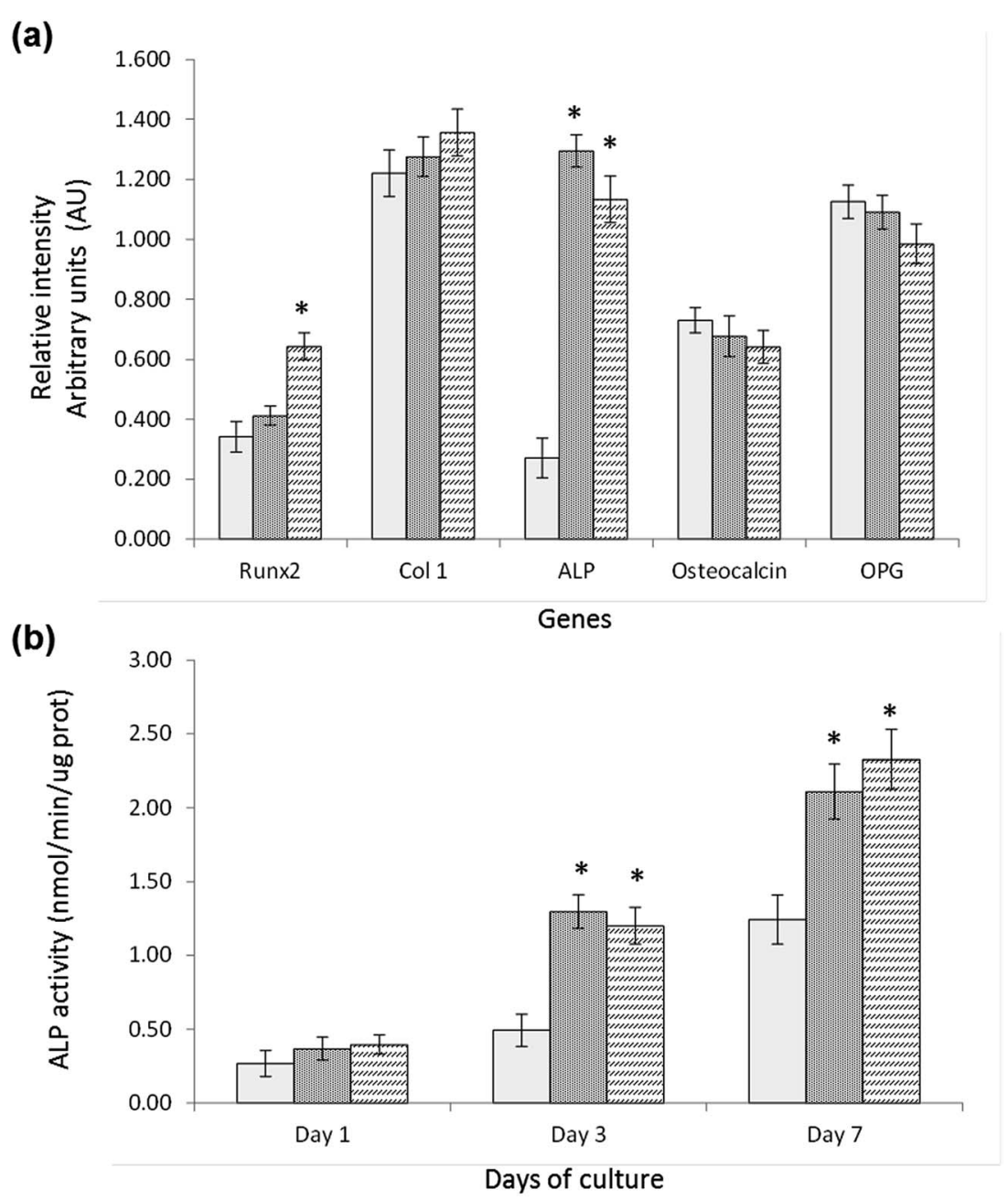

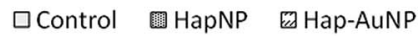

Fig. 9 (a) Gene expression and (b) ALP activity of HMSC cultured in the presence of HapNPs and Hap-AuNPs, $100 \mu g \mathrm{ml}^{-1}$; (a) cultures with 3 days; (b) cultures with 1, 3 and 7 days. *Significantly different from control (absence of NPs). Hap-AuNPs caused a significant increase in the expression of Runx2, and both NPs increased ALP expression and activity. 
HapNP, increased proliferation was found in bone marrowderived mesenchymal stem cells, ${ }^{63}$ and enhanced osteoblastic differentiation features were also observed for these cells, ${ }^{59,63}$ in addition to the osteoblastic cell lines hFOB 1.19 (ref. 62) and MG63. ${ }^{23}$ On the other hand, cytotoxicity/biocompatibility studies involving AuNPs coupled with hydroxyapatite are rare or even non-existent. In regard to AuNPs, the osteoblastic cell response also showed variable results. In the murine preosteoblastic cell line MC3T3-E1, AuNPs did not affect cellular viability; ${ }^{64}$ in another study, they promoted their viability and osteogenic differentiation, depending on the particle size. ${ }^{65}$ In mesenchymal stem cells, AuNPs promoted viability and osteogenic differentiation, ${ }^{\mathbf{6}}$ but they were also reported to be toxic to these stem cells, depending on the particle size. ${ }^{67}$ AuNp aggregation states also influence cellular uptake and cytotoxicity as reported for various cell types, ${ }^{68,69}$ although not following a simple rule of thumb as aggregated AuNP may result in cytotoxicity or favour cell growth depending on the aggregate size, which in turn conditions its internalization. ${ }^{68}$ The conflicting results could also arise from the variability of the applied toxicity assays, cellular systems, and chemical/physical properties of the nanoparticles; moreover, the dosing parameters and exposure times to AuNPs vary, which make comparisons difficult. In the present study, the synthesized Hap-AuNPs showed low cytotoxicity, and this may reflect the use of a system in which small-sized AuNPs are fixed to a HapNP template and thus inhibited from undergoing agglomeration. Hap-AuNPs also exhibited the ability to enhance early phenotype markers for osteogenic differentiation in HMSC, i.e. ALP expression and activity. Furthermore, the considerable increase in the expression of Runx2 is significant, pointing to a higher commitment of mesenchymal stem cells toward the osteogenic lineage in the presence of these particles. In this regard, it has been reported that AuNPs are able to activate the p38 MAPK signalling pathway in the MSCs, which leads to the up-regulation of the osteogenic master transcription factor Runx2, driving MSCs to differentiate toward osteoblast cells. ${ }^{\mathbf{6}}$

The potential of AuNPs for use in numerous different biological applications has led to strong interest in their cellular and tissue compatibility. In this regard, the response of the synthesized Hap-AuNPs towards mesenchymal stem cells seems to substantiate interesting features in bone-related applications from imaging and drug delivery to regenerative approaches. However, their ability to affect the fate of mesenchymal stem cells, i.e. by the enhancement of osteogenic differentiation pathways, should also be carefully considered in bone-related and other biomedical applications.

\section{Conclusions}

Gold nanoparticles (AuNPs) were successfully synthesized on the surface of hydroxyapatite nanoparticles (HapNP). The presence of organic species containing carboxylate groups on HapNP surfaces obtained by the synthetic processes of the HapNPs were a key condition for enabling in situ ionic gold reduction to metal gold, which resulted in spherical AuNPs with a diameter of few nanometers. The presence of nanometric gold on the resulting composite particle (Hap-AuNPs) imparts an SPR effect to the final particles, which may be further explored for imaging and therapeutic purposes. Hap-AuNP interaction with mesenchymal stem cells converged to confirm the nanoparticles cytocompatibility and also their enhancing osteoblastic differentiation properties. In addition, this profile substantiates Hap-AuNPs as promising materials for bone-related applications.

\section{Acknowledgements}

This study was financed by the FEDER, via "Programa Operacional Factores de Competitividade - COMPETE", FCT "Fundação para a Ciência e a Tecnologia”, PEst-C/CTM/LA0011/ 2011, and FMDUP. The authors are grateful to the Portuguese Electronic Microscopy Network for support through FCT funding. CLSM observation was performed at Advanced Light Microscopy, IBMC, University of Porto (IBMC.INEB) under the direction of Dr Paula Sampaio.

\section{References}

1 Y. Xia, Nat. Mater., 2008, 7, 758-760.

2 Y. Zhang, Y. Guo, Y. Xianyu, W. Chen, Y. Zhao and X. Jiang, Adv. Mater., 2013, 25(8), 3802-3819.

3 E. C. Dreaden, A. M. Alkilany, X. Huang, C. J. Murphy and M. A. El-Sayed, Chem. Soc. Rev., 2012, 41(7), 2740-2779.

4 G. von Maltzahn, J.-H. Park, K. Y. Lin, N. Singh, C. Schwöppe, R. Mesters, W. E. Berdel, E. Ruoslahti, M. J. Sailor and S. N. Bhatia, Nat. Mater., 2011, 10, 545-552.

5 G. von Maltzahn, J.-H. Park, A. Agrawal, N. K. Bandaru, S. K. Das, M. J. Sailor and S. N. Bhatia, Cancer Res., 2009, 69(9), 3892-3900.

6 K. Kim, D. Dean, A. Lu, A. G. Mikos and J. P. Fisher, Acta Biomater., 2011, 7(3), 1249-1264.

7 M. Patel, K. J. Patel, J. F. Caccamese, D. P. Coletti, J. J. Sauk and J. P. Fisher, J. Biomed. Mater. Res., Part A, 2010, 94(2), 408-418.

8 S. Yang, D. Wei, D. Wang, M. Phimphilai, P. H. Krebsbach and R. T. Franceschi, J. Bone Miner. Res., 2003, 18(4), 705-715.

9 M. J. Olszta, X. Cheng, S. S. Jee, R. Kumar, Y.-Y. Kim, M. J. Kaufman, E. P. Douglas and L. B. Gower, Mater. Sci. Eng., $R$, 2007, 58(3-5), 77-116.

10 A. Dey, P. H. H. Bomans, F. A. Müller, J. Will, P. M. Frederik, G. de With and N. A. J. M. Sommerdijk, Nat. Mater., 2010, 9, 1010-1014.

11 L. M. Liz-Marzán, M. Giersig and P. Mulvaney, Langmuir, 1996, 12(18), 4329-4335.

12 S. Aryal, R. K. C. Bahadur, S. R. Bhattarai, P. Prabu and H. Y. Kim, J. Mater. Chem., 2006, 16, 4642-4648.

13 Y. Ding, J. Liu, H. Wang, G. Shen and R. Yu, Biomaterials, 2007, 28(12), 2147-2154.

14 T. P. Sastry, J. Sundaraseelan, K. Swarnalatha, S. S. L. Sobhana, M. U. Makheswari, S. Sekar and A. B. Mandal, Nanotechnology, 2008, 19, 245604.

15 Y. Gupta, G. N. Mathur and S. Verma, Bioorg. Med. Chem. Lett., 2006, 16(2), 363-366.

16 S. Arumugan, A. M. Rajam, N. Natarajan, U. Rao, C. Rose and T. P. Sastry, J. Biomed. Nanotechnol., 2006, 2, 46-52. 
17 K. C. R. Bahadur, S. Aryal, N. Bhattarai and H. Y. Kim, Scr. Mater., 2006, 54(12), 2029-2034.

18 J. Turkevich, P. C. Stevenson and J. Hillier, Discuss. Faraday Soc., 1951, 11, 55-75.

19 J. B. Hannon, S. Kodambaka, F. M. Ross and R. M. Tromp, Nature, 2006, 440, 69-71.

20 Y. Wang, S. Zhang, K. Wei, N. Zhao, J. Chen and X. Wang, Mater. Lett., 2006, 60(12), 1484-1487.

21 C. R. Kothapalli, M. Wei, R. Z. Legeros and M. T. Shaw, J. Mater. Sci.: Mater. Med., 2005, 16, 441-446.

22 H. Arce, M. L. Montero, A. Sáenz and V. M. Castaño, Polyhedron, 2004, 23(11), 1897-1901.

23 C. Santos, P. S. Gomes, J. A. Duarte, R. P. Franke, M. M. Almeida, M. E. V. Costa and M. H. Fernandes, J. R. Soc., Interface, 2012, 9, 3397-3410.

24 M. A. Martins, C. Santos, M. M. Almeida and M. E. V. Costa, J. Colloid Interface Sci., 2008, 318, 210-216.

25 S. P. Garcia and S. Semancik, Chem. Mater., 2007, 19(16), 4016-4022.

26 K. Fox, P. A. Tran and N. Tran, ChemPhysChem, 2012, 13(10), 2495-2506.

27 H. Zhou and J. Lee, Acta Biomater., 2011, 7, 2769-2781.

28 S. Link and M. A. El-Sayed, J. Phys. Chem. B, 1999, 103(40), 8410-8426.

29 P. K. Jain, X. Huang, I. H. El-Sayed and M. A. El-Sayed, Plasmonics, 2007, 2(3), 107-118.

30 P. Schneider, Appl. Catal., A, 1995, 129, 157-165.

31 T. Mosmann, J. Immunol. Methods, 1983, 65, 55-63.

32 T. Decker and M.-L. Lohmann-Matthes, J. Immunol. Methods, 1988, 115, 61-69.

33 N. H. D. Leeuw and J. A. L. Rabone, CrystEngComm, 2007, 9, 1178-1186.

34 B. A. J. Noordover, R. Duchateau, R. A. T. M. van Benthem, W. Ming and C. E. Koning, Biomacromolecules, 2007, 8, 3860-3870.

35 D. Jiang and J. Zhang, Curr. Appl. Phys., 2009, 9, S252-S256.

36 S. Bednarz, M. Lukasiewicz, W. Mazela, M. Pajda and W. Kasprzyk, J. Appl. Polym. Sci., 2011, 119, 3511-3520.

37 D. Wyrzykowski, E. Hebanowska, G. Nowak-Wiczk, M. Makowski and L. Chmurzyński, J. Therm. Anal. Calorim., 2011, 104, 731-735.

38 T. B. Mostafa, H. F. Naguib, M. W. Sabaa and S. M. Mokhtar, Polym. Int., 2005, 54, 221-225.

39 G. D. Cody, N. Z. Boctor, R. M. Hazen, J. A. Brandes, H. J. Morowitz and H. S. Yoder Jr, Geochim. Cosmochim. Acta, 2001, 65(20), 3557-3576.

40 S. R. Qiu, A. Wierzbicki, C. A. Orme, A. M. Cody, J. R. Hoyer, G. H. Nancollas, S. Zepeda and J. J. de Yoreo, Proc. Natl. Acad. Sci. U. S. A., 2004, 101, 1811-1815.

41 D. Holzmann, D. Holzinger, G. Hesser, T. Schmidt and G. Knör, J. Mater. Chem., 2009, 19, 8102-8106.

42 C. J. Murphy, A. M. Gole, J. W. Stone, P. N. Sisco, A. M. Alkilany, E. C. Goldsmith and S. C. Baxter, Acc. Chem. Res., 2008, 41, 1721-1730.

43 F. Caruso, M. Spasova, V. Salgueiriño-Macieira and L. M. LizMarzán, Adv. Mater., 2001, 13, 1090-1094.
44 Z. Wang, S. Zong, J. Yiang, J. Li and Y. Cui, Biosens. Bioelectron., 2011, 26(6), 2883-2889.

45 M. Bradley and B. S. Garcia-Risueño, J. Colloid Interface Sci., 2011, 355(2), 321-327.

46 D.-Q. Yang, M. Meunier and E. Sacher, J. Appl. Phys., 2004, 95, 5023-5026.

47 K. van Werde, D. Mondelaers, G. Vanhoyland, D. Nelis, M. K. van Bael, J. Mullens and L. C. van Poucke, J. Mater. Sci., 2002, 37, 81-88.

48 S. Kumar, K. S. Gandhi and R. Kumar, Ind. Eng. Chem. Res., 2004, 46(10), 3128-3136.

49 S. Ivanova, C. Petit and V. Pitchon, Appl. Catal., A, 2004, 267, 191-201.

50 F. Moreau, G. C. Bond and A. O. Taylor, J. Catal., 2005, 231(1), 105-114.

51 K. Zhao, B. Qiao, J. Wang, Y. Zhang and T. Zhang, Chem. Commun., 2011, 47, 1779-1781.

52 J.-D. Wang, J.-K. Liu, Y. Lu, D.-J. Hong and X.-H. Yang, Mater. Res. Bull., 2014, 55, 190-195.

53 A. J. Mieszawska, W. J. M. Mulder, Z. A. Fayad and D. P. Cormode, Mol. Pharmaceutics, 2013, 10(3), 831-847.

54 J. Park, J. Park, E. J. Ju, S. S. Park, J. Choi, J. H. Lee, K. J. Lee, S. H. Shin, E. J. Ko, I. Park, C. Kim, J. J. H. Wang, J. S. Lee, S. Y. Song, S.-Y. Jeong and E. K. Choi, J. Controlled Release, 2015, 207, 77-85.

55 T. Scharnweber, C. Santos, R.-P. Franke, M. M. Almeida and M. E. V. Costa, Molecules, 2008, 13, 2729-2739.

56 Y. Liu, X. Cao, M. Luo, Z. Le and W. Xu, J. Colloid Interface Sci., 2009, 329(2), 244-252.

57 J. P. Bilezikian, L. G. Raisz and T. J. Martin, Principles of Bone Biology, Academic Press, vol. 1, 2008.

58 I. Titushkin, S. Sun, J. Shin and M. Cho, J. Biomed. Biotechnol., 2010, 2010, 1-14.

59 R. Gonzalez-McQuire, D. W. Green, K. A. Partridge, R. O. C. Oreffo, S. Mann and S. A. Davis, Adv. Mater., 2007, 19, 2236-2240.

60 Y. Cai and R. Tang, J. Mater. Chem., 2008, 18, 3775-3787.

61 Z. Shi, X. Huang, Y. Cai, R. Tang and D. Yang, Acta Biomater., 2009, 5(1), 338-345.

62 J. L. Xu, K. A. Khor, J. J. Sui, J. H. Zhang and W. N. Chen, Biomaterials, 2009, 30(29), 5385-5391.

63 Y. Liu, G. Wang, Y. Cai, H. Ji, G. Zhou, X. Zhao, R. Tang and M. Zhang, J. Biomed. Mater. Res., Part A, 2009, 90, 1083-1091.

64 T. Mustafa, F. Watanable, W. Monroe, M. Mahmood, Y. Xu, L. Saeed, A. Karmakar, D. Casciano, S. Ali and A. Biris, J. Nanomed. Nanotechnol., 2011, 2(6), 118-124.

65 D. D. Liu, J. C. Zhang, C. Q. Yi and M. S. Yang, Chin. Sci. Bull., 2010, 55, 1013-1019.

66 C. Yi, D. Liu, C.-C. Fong, J. Zhang and M. Yang, ACS Nano, 2010, 4, 6439-6448.

67 J.-H. Fan, W.-T. Li, W.-I. Hung, C.-P. Chen and J.-M. Yeh, Biomed. Eng., 2011, 23, 141-152.

68 W. Cui, J. Li, Y. Zhang, H. Rong, W. Lu and L. Jiang, Nanomedicine: Nanotechnology, Biology, and Medicine, 2012, 8(1), 46-53.

69 J. A. Yang, S. E. Lohse and C. J. Murphy, Small, 2014, 10, 1642-1651. 